\title{
Structural Characteristics and Genetic Mechanism of Fracture in Shiwu Oilfield
}

\author{
Hu Li \& Qirong Qin \\ Southwest Petroleum University \\ Chengdu Sichuan 610500, China \\ E-mail: 349274410@qq.com \\ Wenhua Tang \\ Drilling \& Pruducing Company of Zhongyuan oilfield \\ Puyang Henan 457001, China \\ E-mail: tangwenhua2000@163.com \\ Mingyuan Tang \\ Yan Chi producing factory of Huabei Petroleum \\ Ning Xia 751500, China \\ E-mail: tmytx119840120@163.com
}

\begin{abstract}
Based on the core, chip,drilling, Seismic data,etc,Combining the tectonic evolution of shiwu fault, comprehensive study the Charcteristics of Structural, fracture and the genetic mechanism of fracture.after study:on the basis of the reaearch on the Xiaokuan fault and nearby north-south faults, 6 secondary structure units are divided.They are: Xiaokuan extrusion and strike-slip zone,Qikeshu syncline belt,Dawujiazi and Xiaowujiazi fault belt,Nanling fault terrace,and Liangjiatun fault terrace.after study on the length and density by Weighting Process, Crack is developed in Shiwu Oilfield;it is affected by five tectonic movements and formed the four periods fracture; extensional directions of these fractures are NE,SN,NW,NNE,NNW,EW, etc.
\end{abstract}

Keywords: Structural Charcteristics, Fracture, Genetic mechanism, Weighting Process, Shiwu Oilfield

\section{Research Area Site}

Shiwu Oilfield located at the boundaries of Gongzhuling of Jilin Province, QinJiatun Oilfield is in the east, Siwujiazi Oilfield is in the south and Taipingzhuang Oilfield is in the Northeast. Research area approximately is $100 \mathrm{~km}^{2}$. it is in the tectonic belt of Siwujiazi structure, The conformation is a large-scale broken-nose structure(Liying Yang, Ruilei Li \& Jiangtao Zhang. 2005)(Kai Yu, Zhensheng Yang\& Baiping Yao. 2000) The tectonic movement of research area is intense and structural features is complicated, it developed a series of fault with NE,NNE,NNW and SN position, Structural form showing the characteristic of North East is high and Southwest is low, Structure fracture growth.

\section{Structural Features}

\subsection{Division of Tectonic Units}

Under the control of Xiaokuan fault,Bawu, Daijiatun,Nanling faults present to western-leaning volts and control the local sedimentary of fault period. According to the segmentation of these faults (Haibo Bai. 2002)( Yunsheng Wang\& Shitian Wang. 2000)(Danping Yan\& Xinwen Wang. 2000),we divided Shiwu Oilfield into the following six tectonic units. Its main characteristics are as follows:

(1) Xiaokuan extrusion and strike-slip zone

It is mainly fault zone as the result of the left-lateral strike-slip of Xiaokuan fault, located on both sides of Xiaokuan fault and face stretching along SW-NE to TaiPingzhuang,nearby TaiPingzhuang, Negative flower structure of Xiaokuan fault is more obvious.in the south of Xiaokuan fault,it has derived a NE reverse slip fault,what is more, it has associated a regulation fault with nearly EW trending, nearly SN,NNW ,NNE en echelon fault and NE abnormal fault. At the same time, it also formed Siwujiazi anticline with NE axial direction, The north side was cut into two north-south, The south side extend to Qikeshu syncline belt. 


\section{(2) Qikeshu Syncline Belt}

It located between Xiaowujiazi fault belt and Qinjiatun fault belt, and it is a west plunging, north-south direction cocked syncline. Fault subsidence lay showed overlapping In the NE direction, relatively stable, faults developed very simple, and it is easy to form litho stratigraphic reservoir.

(3) Dawujiazi and Xiaowujiazi fault belt, Nanling fault terrace, and Liangjiatun fault terrace

These 4 fault belts are situated at the north of Xiaokuan fault,it is formed from west to east in development, the main foundation of the division:Bawu,Daijiatun,Nanling faults Nearly NS direction ,it is formed earlier. Fault belts had been strike slip displacement last stage of Yingcheng formation and last stage of Denglouku formation most intense period,under the control of Xiaokuan extrusion and strike-slip zone and affected by the sinistral strike slip,it associated with the formation of nearly SN,NNE,NNW faults etc.in the cut plane, it showed negative flower,cabbage-like constructive style.

\subsection{Fracture Activities Features}

Fracture activities is intense in Shiwu Oilfield,which developed second order fault zone that control structure , developed third order fault zone control traps and block pattern, also developed forth order fault zone, The main fracture characteristics as follows:

Xiaokuan fault: second order fault zone that to the NE overall, Xiaokuan fault acceptted by compression efficiency nearby Xiaowujiazi, it showed positive flower in profile and the thrust is intense, there is a tendency of being thick in Yingcheng formation and overlying formation. It developed a series of en echelon faults within the zone,which become favorable zones of the gas and oil mixed together.Xiaokuan fault take this as the stress release centre,developed negative flower structure in the east and west, especially in the NE of low angle of bedding.Xiaokuan fault control the sedimentary of early SE faulted depression layer,Huoshilin and Shahezi formation east thin with cuneal, amplitude $20-500 \mathrm{~m}$, fractured surface dip about $50^{\circ}$, trend SSE, abrupt stratigraphic position $\mathrm{T}_{3}-\mathrm{T}_{5}$, and it is an important fault which control the tectonic belt that developed at early phase,affected by sinistral strike slip in the end of Yingcheng and Denglouku formation.

Bawu fault:third order fault zone,that is a centripetal fault which near SN trend, the trend of the south near Xiaokuan fault is NWW and the trend of the north is west.the extention of the fault is about $11 \mathrm{~km}$, amplitude 10-180m; abrupt stratigraphic position $\mathrm{T}_{3}-\mathrm{T}_{5}$, fractured surface form is steeper at the upper portion and gentler in the lower portion,it control the sedimentary of Shahezi and ahove formation,and it is an important fault that control block framework and sedimentary which affected by extensional movement of early fault depression,strike slip motion of lately fault depression and reverse motion of later sunken.

Daijiatun fault: third order fault zone, that is a centripetal fault which near SN trend, the trend of the south is west, the trend of the north is NWW, the extention of the fault is about $11 \mathrm{~km}$, amplitude $10-180 \mathrm{~m}$, abrupt stratigraphic position $T_{3}-T_{5}$.it is a a centripetal fault control block framework and local sedimentary which developed in multistage movement.

Nanling fault: third order fault zone, that is a NNE trend centripetal fault, the extention of the fault is about $8 \mathrm{~km}$, abrupt stratigraphic position $\mathrm{T}_{3}-\mathrm{T}_{5}$.it is a a centripetal fault control block framework and local sedimentary which developed in multistage movement.

\section{Development degree and genetic mechanism of Structural fracture}

Through the observation and statistics of core crack of the coring Wells in reaserching area(Chuan Guo, Yushuang Zhu\& Wenqing Li. 2009)( Xinguo Zhang, Qirong Qin\& Jin Huo. 2007), large-scale fracture (> 20cm) accounted for $20 \%$, Medium-scale fracture (2 to $20 \mathrm{~cm}$ ) accounted for more than $70 \%$, Small fracture $(0.2$ to $2 \mathrm{~cm})$ and micro-fracture $(<0.2 \mathrm{~cm})$ accounted for less than $10 \%$. The main range of crack width is below $1 \mathrm{~mm}$, and besides is 1 to $2 \mathrm{~mm}$, accounted for more than $20 \%$, other range of width are relatively few. What must point out specially, fractures that range of crack width beyond $5 \mathrm{~mm}$ also accounted for the greater proportion, so it shows fracture width is relatively big. Density of fracture focused on the range that the density is less than $0.2 \mathrm{strip} / \mathrm{m}$, about accounting for $65 \%$ in all fracture-riched sections. Besides, the density of fracture is more than or equal to $0.6 \mathrm{strip} / \mathrm{m}$, accounting for $20 \%$ in all fracture-riched sections; and the fracture that density is 0.2 to $0.4 \mathrm{strip} / \mathrm{m}$ accounted for $15 \%$ in all fracture-riched sections.

As a result of the multiperiodic tectonic action, the tectonic feature of Shiwu Oilfiled accord with the sedimentation development history .According to the feature of regional structural stress field development, field investigation, observation of drill core and the multidisciplinary analysis of log interpretation(Ziliang Liu\& Chunxiu Liang. 1999)(Yinli Chen, Yang Gu \& Chen Guming. 2008), the author come to the conclusion that the 
fractures of research area are mainly generated by several tectonic movement.

Yingcheng tectonic movement is a small-scale tectonic inversion movement in the stage of rift evolution , resulting of the rift basin uplift and denudation in different levels. The tectonic stress field is the compressive stress field which tends the North West - South East. This compressive stress, forming a nearly north-south $\left(10^{\circ}\right.$ $\left.\pm 15^{\circ}\right)$ and the North West to $\left(290^{\circ} \pm 15^{\circ}\right)$ high-angle conjugate shear fractures, NW $\left(330^{\circ} \pm 15^{\circ}\right)$ gash fracture, but also developed in the vicinity of Xiaokuan trending faults $\left(45^{\circ} \pm 15^{\circ}\right)$ which associated with low-angle shear fractures. Nearly north-south $\left(10^{\circ} \pm 15^{\circ}\right)$ fracture development intensity, and NWW $\left(290^{\circ} \pm\right.$ $15^{\circ}$ ) fracture development is weak, $\mathrm{NE}\left(45^{\circ} \pm 15^{\circ}\right)$ near the crack developed in the comparative fault Xiaokuan intensive, breaking away from the Xiaokuan sparse.

Denglouku formation occurred during the deposition reverses of the tectonic stress. The ectonic stress field in the North West - South East, to the tensile stress field. Cracks in the original development of Shiwu oil field were pulled, sewn into a tension cracks by tensile stress. Meanwhile, earlier pulled after pressure stress field, there are more of the twisted sheets sewn.

Denglouku formation final rift basin tectonic movement led to the depression phase of the transformation stage, the tectonic fault movement is an important form of local structures of the period is also important during the early formation of hydrocarbon reservoirs. It generates the uplift and erosion in the southeast uplift pear rift within the most obvious. Denglouku formaton final stress field is the same with Yingcheng formation, for the North West - South East to the compressive stress, but stress intensity increases. In this stress, the cracks of Yingcheng formation in the board late last movement has been strengthened. Fracture is greater than the end of Yingcheng formation, some cracks develop into north-south fracture strike-slip fault.

Tectonic movement during the late Nenjiang is the most important tectonic rollover movement of Songliao basin. Shiwu oil field were effected by Tan-Lu fault slip and a sinistral transpressional stress field.In this stress field, Xiaokuan fault turned to the left-lateral slip fault and also been pressed, some part of this fault reversed to reversal fault.Early formation of the joint part of the north-southcut open, east-west fracture closure; also formed a NNE $\left(35^{\circ} \pm 15^{\circ}\right)$ and $\mathrm{NW}\left(330^{\circ} \pm 15^{\circ}\right)$ of the "X"-type high angle conjugate shear fractures, the tensional fractureformed during the late of yingcheng group and the denglouku group was formed by the late Zhang crack shape as the sheets are cut twisted joints, cracks due to the formation period of this group of late, many cracks were not filled; the Xiaokuan strike-slip fault in the development of a small amount around the fault is also derived seam.

Mingshui tectonic movement is another tectonic rollover movement, mainly impact the middle and western region in the Songliao basin and resulted in regional uplift, folding, erosion, as the important period of the structural formation and shaping in the central depression area and the western slope ,but the tectonic movement did little affection to the southeast uplift area ,so the Mingshui tectonic movement just reworked the Early formation cracks.

Association the structural analysis with structural evolution rule of ShiWu oil field , the author believe that there are four terms of fractures in reaserching area, but the tectonic movement at the late MingShui group only rebuilds the early fractures, not causes new fractures yet (as shown in Table 1).

\section{Conclusion}

In the basis of the structure interpretation, According to the distribution characteristics and the control of zones of Xiaokuan fault,Bawu fault,Daijiatun fault and Nanling fault, 6 secondary structure units are divided. there are six time of stages of tectonic movement in Shiwu area:intial stage faulted depression, last stage of huoshiling formation, last stage of yingcheng formation, last stage of denglouku formation, last stage of nenjiang formation, last stage of mingshui formation.

Fracture is relatively developed in in Shiwu Oilfield, Width is broader, the length is longer. there are six extensional directions of these fractures are NE,SN,NW,NNE,NNW,EW, etc.

\section{References}

Chuan Guo, Yushuang Zhu \& Wenqing Li. (2009). Fracture characteristics of Chang 6 reservoir in Pingqiao area of Ansai Oilfield. Journal of Northwest University(Natural Science Edition).

Danping Yan\& Xinwen Wang. (2000). Analysis of fold style and It's formation mechanism in the area of boundary among Sichuan,Hubei and Hunan. Geoscience-journal of graduate school china university of geosciences.

Haibo Bai. (2002). Research on formation mechanism of earth fissure in Xuzhou coal mining area. Coal geology 
\& exploration.

Hengmao Tong\& Daiyong Cao. (2004). Genesis and distribution pattern of fractures in western Qaidam basin. Oil \& Gas Geology.

Kai Yu, Zhensheng Yang\& Baiping Yao. (2000). Structural framwork evolution in ShiWu fault depression and its relation to oil and gas. Natural gas industr.

Liying Yang, Ruilei Li \& Jiangtao Zhang. (2005). Structural characteristics of Lishu fault in the southeastern uplift area of the Songliao basin. Progress in Geophysics.

Xinguo Zhang, Qirong Qin\& Jin Huo. (2007). characteristics of the fractures in carboniferous reservoirs, at the zone 9, kramay oil-field. Journal of Southwest Petroleum University.

Yinli Chen, Yang Gu\&Chen Guming. (2008). Characteristics and stages of fractures in the second member of xujiahe formation in Qiongxi structure, western Sichuan depression. Natural Gas Industry.

Yunsheng Wang\& Shitian Wang. (2000). The genetic mechanism analysis of the nappes in the Jianghuan-Heqing region, Yunnan. Joural of Chengdu university of technology.

Ziliang Liu\& Chunxiu Liang. (1999). Genetic mechanism and distribution direction of structural fracture in southern Songliao basin. Petroleum exploration and development.

Table 1. Fracture terms table of Shiwu Oilfield

\begin{tabular}{|c|c|c|c|}
\hline Term & Period & Stress orientation & fracture orientation and type \\
\hline 1 & $\begin{array}{l}\text { last stage of } \\
\text { yingcheng formation }\end{array}$ & NW & $\begin{array}{lc}\text { SN } & \text { High angle adjoint shear fracture } \\
\text { NWW } & \text { High angle adjoint shear fracture } \\
\text { NW } & \text { Extension fracture } \\
\text { NE } & \text { Low angle accompany shear fracture }\end{array}$ \\
\hline 2 & $\begin{array}{l}\text { last stage of } \\
\text { denglouku formation }\end{array}$ & NW & $\begin{array}{ll}\text { SN } & \\
\text { NWW } & \\
\text { NW } & \text { Extension fracture } \\
\text { NE } & \text { Accompany shear fracture }\end{array}$ \\
\hline \multirow[t]{2}{*}{3} & \multirow[t]{2}{*}{$\begin{array}{l}\text { last stage of } \\
\text { nenjiangformation }\end{array}$} & \multirow[t]{2}{*}{$\begin{array}{l}\text { left-lateral strike-slip } \\
\text { stress }\end{array}$} & $\begin{array}{l}\text { NE "X" high angle adjoint shear fracture } \\
\text { NW "X" high angle adjoint shear fracture } \\
\text { SN shear fracture open,NWW hear fracture close }\end{array}$ \\
\hline & & & NW fracture change to tenso shear fracture \\
\hline 4 & $\begin{array}{l}\text { last stage of mingshui } \\
\text { formation }\end{array}$ & - & - \\
\hline
\end{tabular}

